Вестник Новосибирского государственного педагогического университета Novosibirsk State Pedagogical University Bulletin

1(17) $2014 \quad$ www.vestnik.nspu.ru ISSN 2226-3365

(C) E. В. Васина, Н. Н. Кошко

\title{
УДК 614+371.7
}

\section{АДАПТАЦИЯ ПОДРОСТКОВ В ПРОЦЕССЕ ОБУЧЕНИЯ ПО РАЗНЫМ ПРОФИЛЬНЫМ ПРОГРАММАМ*}

\author{
Е. В. Васина, Н. Н. Кошко (Кемерово, Россия)
}

В статье приводятся результаты исследования адаптивных изменений возникаюших у учашихся в прочессе обучения по разным профильным программам с 8 по 11 класс. Цель статьи - обосновать, что адаптаџия старшеклассников к обучению зависит от сложности и содержания учебной деятельности. Отмечается, что на предпрофильном и профильном этапах обучения проявления адаптивных реакций у подростков различается. При увеличении учебной нагрузки с переходом на профильный этап обучения напряжение систем вегетативной регуляциии сердечного ритма у школьников всех профилей усиливается. В ходе обучения по программам разных профилей у подростков наблюдается различия в изменении параметров сердечного ритма. Наибольшее напряжение установлено у учащчихся лингвистического и физикоматематического профилей обучения.

Ключевые слова: адаптация, учащчеся, профиль обучения, вариабельность сердечного ритма, напряжение механизмов вегетативной регуляции.

Реакция системы кровообращения, особенно характер изменений сердечного ритма у детей и подростков при информационных и эмоциональных нагрузках, позволяет оценить функциональные резервы, мобилизацию и расходование оперативных и стратегических ресурсов организма на этапах срочной и долговременной адаптации [1-2; 4]. В настоящее время особую актуальность приобретают вопросы изучения адаптации подростков к обучению, в целом [3; 8-9], профильному обучению, - в частности [4]. Профильное обучение характеризуется значительной силой и интенсивностью воздействия из-за сложности изучаемых предметов и большого объема учебной нагрузки [11].

\footnotetext{
* Статья подготовлена по результатам работы Всероссийской научной школы с Международным участием «Опыт использования мониторинга здоровья и физической подготовленности учащейся молодежи» (12-14 ноября 2013 г.).
}

Васина Евгения Владимировна - кандидат биологических наук, заведующий лабораторией развития здоровьесберегающей деятельности в системе профессионального образования, Кузбасский региональный институт развития профессионального образования.

E-mail: ev-va08@mail.ru

Кошко Наталья Николаевна - кандидат биологических наук, преподаватель кафедры физиологии человека и животных и валеологии, Кемеровский государственный университет.

E-mail: koshko80@mail.ru 
Вестник Новосибирского государственного педагогического университета Novosibirsk State Pedagogical University Bulletin

Продолжительное действие этих факторов обусловливает функциональные, адаптационные изменения в организме учащихся. В связи с этим, в условиях возросших требований к адаптационным возможностям подростков, обучающихся в профильных классах, особый интерес представляет изучение вариабельности сердечного ритма у учащихся разных профильных классов на протяжении предпрофильного и профильного обучения.

С этой целью у одних и тех же подростков в динамике 4 лет ежегодно оценивалось состояние регуляторных систем организма по показателям вариабельности сердечного ритма (ВСР) в покое и при выполнении ортопробы по методике Р.М. Баевского (2002) при помощи автоматизированного комплекса «ORTO Expert» [6]. При анализе сердечного ритма оценивались показатели: частота сердечных сокращений (ЧСС), мода (Мо), амплитуда моды (АМо), вариационный размах $(\Delta \mathrm{X})$, индекс напряжения регуляторных си-

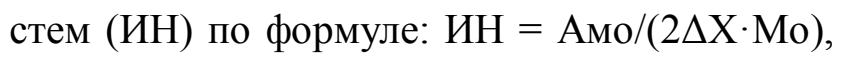
показатели спектрального анализа сердечного ритма (TF, HF, LF, VLF). В исследовании участвовали 372 гимназиста в возрасте от 13 до 17 лет, обучающиеся в с 8 по 11 класс по естественно-математическому направлению (физико-математический и химикобиологический профили) и по гуманитарному профилю (лингвистический и историкофилологический профили). Контрольной группой являлись учащиеся общеобразовательных классов того же возраста в количестве 672 человек.

В результате проведенного исследования выявлено, что обучение в течение 4 лет на повышенном образовательном уровне сопровождалось разнонаправленными изменениями показателей ВСР у учащихся разных профилей обучения. Анализ показателей ВСР у восьмиклассников разных профилей обучения показал, что значение индекса напряжения в покое (ИН) - интегрального показателя, отражающего уровень напряжения механизмов регуляции сердечного ритма не различается у гимназистов разных профилей обучения и общеобразовательных классов и отражает неоптимальный уровень функционирования сердечно-сосудистой системы, за счет напряжения регуляторных механизмов характерный для подросткового возраста [7; 10]. В связи с этим от 27 до $35 \%$ восьмиклассников характеризуются увеличением влияния симпатического отдела ВНС в регуляции сердечного ритма (Табл. 1; Рис. 1).

Дальнейшее Формирования адаптивного ответа организма подростков на длительное влияние факторов образовательной среды в процессе обучения различалось в зависимости от профиля обучения. Так у учащихся ФМ, ХБ и ИФ профилей в 9 классе происходит увеличение парасимпатических влияний на сердечный ритм, о чем свидетельствует снижение ЧСС и увеличение $\Delta \mathrm{X}$ у гимназистов ФМ профиля и снижению показателей ИН в ортостазе у учащихся ХБ профиля (Табл. 1). У гимназистов ГМ профиля наблюдается более выраженная реакция: значительное снижение ИН, АМО, увеличение $\Delta \mathrm{X}$ и увеличение числа лиц с повышенным влиянием парасимпатического отдела ВНС на СР почти в 2 раза, свидетельствующее о снижении уровня функционирования ССС (Табл. 1; Рис. 1). У девятиклассников ИФ профилей наблюдается увеличение спектральной мощности волновой структуры сердечного ритма (TF,VLF, LF, HF), связано, по мнению Р.М. Баевскиого и соавт. с активацией высших вегетативных центров. У гимна- 
Вестник Новосибирского государственного педагогического университета Novosibirsk State Pedagogical University Bulletin

зистов ЛГ профиля от 8 к 9 классу происходит значительное повышение ИН в ортостазе и АМо в покое (Табл. 1). Количество лиц с увеличенным влиянием симпатического отдела ВНС в регуляции СР возрастает более чем в 2 раза (Рис. 1).

Таблица 1

Динамика показателей вариабельности сердечного ритма у учащихся разных профилей обучения с 8 по 11 класс

\begin{tabular}{|c|c|c|c|c|c|c|c|}
\hline \multirow{3}{*}{$\begin{array}{c}\text { Пока- } \\
\text { зате- } \\
\text { ли }\end{array}$} & \multirow{3}{*}{$\begin{array}{l}\mathrm{K} \\
Л \\
\mathrm{~A} \\
\mathrm{C} \\
\mathrm{C}\end{array}$} & \multicolumn{2}{|c|}{$\begin{array}{c}\text { Естественно-математическое } \\
\text { направление }\end{array}$} & \multicolumn{2}{|c|}{ Гуманитарное направление } & \multirow[b]{2}{*}{$\begin{array}{c}\text { Общеобразо- } \\
\text { вательные } \\
\text { классы } \\
\text { n }=245\end{array}$} & \multirow{3}{*}{$\begin{array}{c}\text { Достовер- } \\
\text { ность } \\
\text { различий } \\
\text { p }<0,05\end{array}$} \\
\hline & & $\begin{array}{c}\text { Физико- } \\
\text { математический } \\
\text { профиль } \\
\text { n = } 115\end{array}$ & $\begin{array}{c}\text { Химико- } \\
\text { биологи- } \\
\text { ческий профиль } \\
\mathrm{n}=86\end{array}$ & $\begin{array}{c}\text { Лингвисти- } \\
\text { ческий } \\
\text { профиль } \\
\mathrm{n}=81 \\
\end{array}$ & $\begin{array}{c}\text { Историко- } \\
\text { филологи- } \\
\text { ческий } \\
\text { профиль } \\
\text { n=90 }\end{array}$ & & \\
\hline & & 1 & 2 & 3 & 4 & 5 & \\
\hline \multirow{4}{*}{$\begin{array}{l}\text { ЧСС } \\
\text { по- } \\
\text { кой, } \\
\text { уд / } \\
\text { мин }\end{array}$} & 8 & $85,9 \pm 1,3$ & $82,9 \pm 1,9$ & $86,6 \pm 1,7$ & $85,7 \pm 1,4$ & $85,6 \pm 0,75$ & нет \\
\hline & 9 & $79,3 \pm 1,7^{*}$ & $84,3 \pm 1,8$ & $87,1 \pm 1,7$ & $73,7 \pm 1,6^{*}$ & $85,8 \pm 1,3$ & $\begin{array}{l}1-2,3,4,5 ; 4 \\
-2,3,5\end{array}$ \\
\hline & 10 & $87,2 \pm 2,0^{*}$ & $81,2 \pm 2,0$ & $83,9 \pm 1,6^{*}$ & $78,9 \pm 1,8^{*}$ & $82,3 \pm 0,9$ & $\begin{array}{l}4-1,3,5 \\
1-5\end{array}$ \\
\hline & 11 & $82,3 \pm 2,0^{*}$ & $80,2 \pm 1,7$ & $82,6 \pm 2,7$ & $83,0 \pm 2,6^{*}$ & $82,5 \pm 1,1$ & нет \\
\hline \multirow{4}{*}{$\begin{array}{l}\text { ИН } \\
\text { по- } \\
\text { кой, } \\
\text { усл. } \\
\text { ед. }\end{array}$} & 8 & $167,2+15,7$ & $195,9 \pm 15,3$ & $196,5 \pm 13,7$ & $163,3 \pm 19,7$ & $172,4 \pm 13,3$ & нет \\
\hline & 9 & $143,7 \pm 19,9$ & $211,7 \pm 20,7$ & $212,3 \pm 24,7$ & $110,9 \pm 20,9^{*}$ & $186,7 \pm 18,2$ & $1,4-2,3,5$ \\
\hline & 10 & $259,9 \pm 24,6^{*}$ & $164,2+21,8^{*}$ & $227,0 \pm 17,6$ & $184,2 \pm 17,2^{*}$ & $184,3 \pm 17,9$ & $1-2,4,5 ; 2-3$ \\
\hline & 11 & $220,6 \pm 19,1$ & $141,7 \pm 24,4$ & $256,4 \pm 14,8$ & $174,3 \pm 20,6$ & $154,5 \pm 15,7$ & $1,3-2,4,5$ \\
\hline \multirow{4}{*}{$\begin{array}{l}\text { ИН } \\
\text { нагруз } \\
\text { ка, } \\
\text { усл. } \\
\text { ед. }\end{array}$} & 8 & $395,7 \pm 29,9$ & $412,6 \pm 22,9$ & $426,1 \pm 29,1$ & $438,2 \pm 31,1$ & $294,8 \pm 24,8$ & $5-1,2,3,4$ \\
\hline & 9 & $325,1 \pm 28,9$ & $349,2 \pm 22,1^{*}$ & $508,9 \pm 39,7^{*}$ & $221,9 \pm 24,9^{*}$ & $356,2 \pm 31,2$ & $\begin{array}{l}3-1,2,4,5 \\
4-1,2,5\end{array}$ \\
\hline & 10 & $484,7 \pm 24,0^{*}$ & $417,5 \pm 29,6^{*}$ & $495,9 \pm 24,1$ & $395,1 \pm 29,3^{*}$ & $281,4 \pm 27,9$ & $\begin{array}{l}5-1,2,3,4 \\
1-4 ; 3-2,4\end{array}$ \\
\hline & 11 & $472,2 \pm 27,4$ & $403,2 \pm 31,8$ & $542,1 \pm 36,2$ & $438,7 \pm 38,2$ & $382,6 \pm 30,9$ & $\begin{array}{l}3-1,2,3,5 \\
1-2,5\end{array}$ \\
\hline \multirow{4}{*}{$\begin{array}{l}\text { AMO } \\
\text { по- } \\
\text { кой, } \\
\%\end{array}$} & 8 & $41,1 \pm 1,8$ & $40,2 \pm 2,9$ & $42,8 \pm 2,2$ & $41,1 \pm 2,1$ & $41,8 \pm 1,2$ & нет \\
\hline & 9 & $40,1 \pm 2,5$ & $46,1 \pm 3,5$ & $48,1 \pm 2,2^{*}$ & $34,2 \pm 3,2^{*}$ & $43,6 \pm 1,4$ & $\begin{array}{l}3-1,5 \\
4-2,3,5 \\
\end{array}$ \\
\hline & 10 & $45,9 \pm 3,1$ & $40,3 \pm 2,8$ & $47,1 \pm 2,2$ & $43,2 \pm 2,4^{*}$ & $42,1 \pm 1,3$ & $3-2,5$ \\
\hline & 11 & $44,0 \pm 3,0$ & $40,7 \pm 2,9$ & $51,6 \pm 3,0$ & $44,8 \pm 2,9$ & $40,8 \pm 1,6$ & $3-1,2,5$ \\
\hline \multirow{4}{*}{$\begin{array}{l}\Delta \mathrm{X} \\
\text { по- } \\
\text { кой, } \\
\text { Сек }\end{array}$} & 8 & $0,24 \pm 0,01$ & $0,27 \pm 0,02$ & $0,25 \pm 0,02$ & $0,28 \pm 0,01$ & $0,26 \pm 0,01$ & $1-4$ \\
\hline & 9 & $0,31 \pm 0,02^{*}$ & $0,27 \pm 0,03$ & $0,24 \pm 0,02$ & $0,38 \pm 0,03^{*}$ & $0,25 \pm 0,02$ & $\begin{array}{l}4-1,2,3,5 \\
1-3,5\end{array}$ \\
\hline & 10 & $0,28 \pm 0,02$ & $0,29 \pm 0,02$ & $0,24 \pm 0,02$ & $0,29 \pm 0,03^{*}$ & $0,30 \pm 0,02$ & $3-5$ \\
\hline & 11 & $0,28+0,02$ & $0,34 \pm 0,03^{*}$ & $0,24 \pm 0,02$ & $0,30 \pm 0,03$ & $0,34 \pm 0,02$ & $2,5-1,3$ \\
\hline
\end{tabular}


Вестник Новосибирского государственного педагогического университета Novosibirsk State Pedagogical University Bulletin

1(17) $2014 \quad$ www.vestnik.nspu.ru ISSN 2226-3365

Рисунок 1

Изменение состояния систем вегетативной регуляиии сердечного ритма у гимназистов разных профилей обучения от $8 \kappa 11$ классу

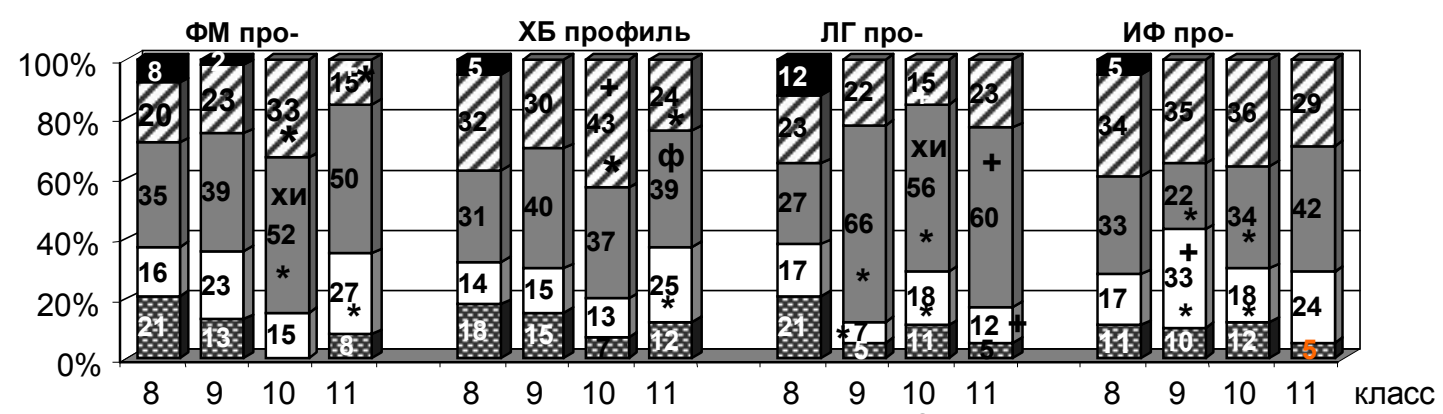

снижение тонуса симпатического и парасимпатического отделов ВНС

\рассогласование симпатического и парасимпатического отделов ВНС 圈 нормальное

$\square$ увеличенное влияние симпатического отдела ВН $\square$ увеличенное влияние парасимпатического отдела ВНС

Примечание - достоверность различий по сравнению с предыдущим годом в профиле:

* - $<<0,05$; от других профилей одного года обучения: $+-\mathrm{p}<0,05$, от ФМ профиля: $\boldsymbol{\phi}-\mathrm{p}<0,05$, от ХБ профиля: $\mathbf{x}-\mathrm{p}<0,05$, от ИФ профиля: $\mathbf{и}-\mathrm{p}<0,05$.

Изменение вегетативного баланса в виде активации симпатического отдела ВНС рассматривается как неспецифический компонент адаптационной реакции в ответ на различные стрессорные воздействия среды [3; 5 и др.].

У десятиклассников ХБ профиля ИН в покое снижается, а в ортостазе - увеличивается ( $<<0,05)$, что свидетельствует о повышении реактивности организма и включении компенсаторных реакций при нагрузочной пробе. В подтверждение этого, количество лиц с рассогласованием влияний симпатического и парасимпатического отделов ВНС и со значительным напряжением механизмов регуляции сердечного ритма увеличивается в 10 классе до $43 \%$ (Рис. 1, 2).

Увеличение обшей мощности спектральных характеристик сердечного ритма (TR, VLF, LF, HF) свидетельствует о возрастании центральных влияний на сердечный ритм [12]. Совокупность неблагоприятных реакций, вероятно, вызвана увеличением учебной нагрузки с переходом на профильную ступень обучения. В 11 классе у гимназистов ХБ профиля наблюдаются более благоприятные адаптационные изменения в регуляции сердечной деятельности: снижается количество лиц со значительным напряжением механизмов регуляции, возрастает парасимпатическая активность в управлении сердечным ритмом, на что указывает увеличение $\Delta \mathrm{X}$ и увеличение количества лиц с повышенным влиянием парасимпатического отдела ВНС в регуляции сердечным ритмом (Рис. 1, 2). Снижение мощности диапазона VLF свидетельствует об уменьшении влияний центрального контура управления на сердечный ритм. Значения индекса напряжения в покое соответствует возрастной норме и ниже, чем у одиннадцатиклассников ФМ и ЛГ профилей $(\mathrm{p}<0,05)$, что указывает на отсутствие напряжения механизмов вегетативной регуляции. 
Вестник Новосибирского государственного педагогического университета Novosibirsk State Pedagogical University Bulletin

1(17) $2014 \quad$ www.vestnik.nspu.ru ISSN 2226-3365

Рисунок 2

Изменение функционального состояния организма учащихся разных профилей в динамике четьрехлетнего обучения с 8 по 11 класс

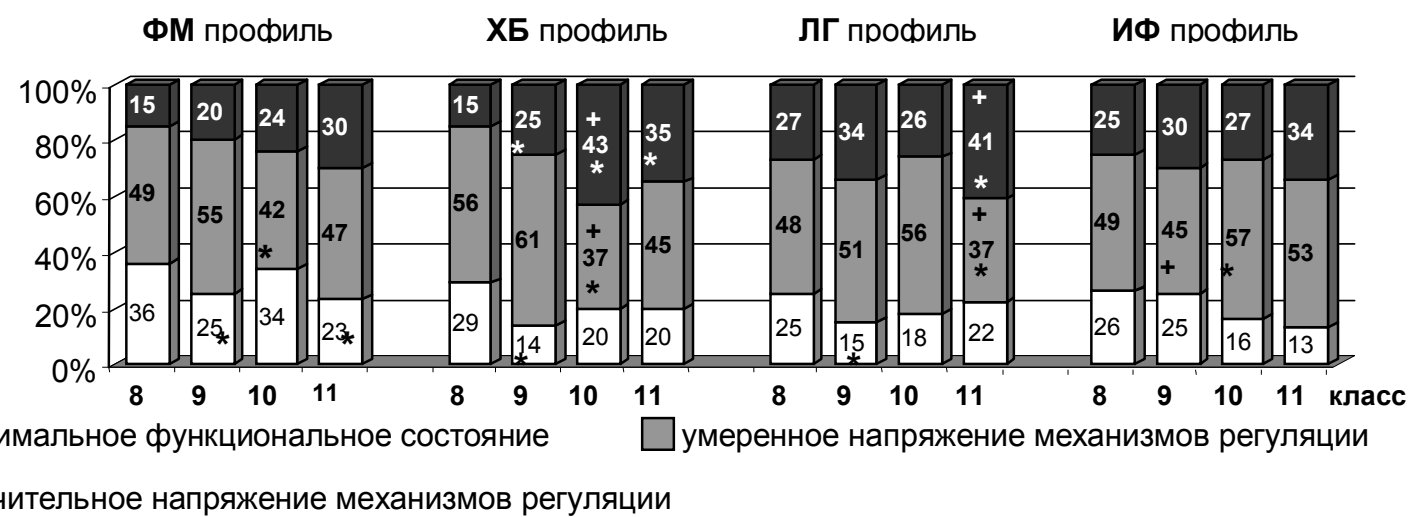

Примечание - достоверность различий по сравнению с предыдущим годом в одном профиле: * $-\mathrm{p}<0,05$; между разными профилями одного года обучения: $+-\mathrm{p}<0,05$.

У учащихся ЛГ профиля высокие показатели ИН сохраняются до 11 класса и имеют тенденцию к увеличению (Табл. 1). В результате этого одиннадцатиклассники ЛГ профиля отличаются от гимназистов ИФ и ХБ профилей и школьников общеобразовательных классов высоким значением ИН в покое и высоким значением ИН в ортостазе от учащихся всех групп $(p<0,05)$. Снижение показателя $\mathrm{HF}$ - маркера активности парасимпатической нервной системы в 11 классе свидетельствует об увеличении симпатических влияний на сердечный ритм, не свойственном данному возрасту [6]. Группа учащихся с неудовлетворительной адаптацией увеличивается до $41 \%$, а с увеличенным влиянием симпатического отдела ВНС в регуляции сердечного ритма составляет $60 \%$, что достоверно превышает аналогичные группы учащихся других профилей (Рис. 1, 2). Полученные данные свидетельствуют о неблагоприятном функциональном состоянии организма у гимназистов ЛГ профиля на протяжении всего периода профильного обучения. У старшеклассников ГМ профиля в 10 классе наблюдается увеличение симпатической активности: повышение ИН, АМо, снижение $\Delta \mathrm{X}$ в покое и ортостазе и увеличивается количество лиц с увеличенным влиянием симпатического отдела ВНС в регуляции сердечного ритма. В 11 классе наблюдается тенденция к увеличению АМО, ИН в ортостазе, но статистически значимо увеличивается только ЧСС в покое. Значения ИН у гимназистов этого профиля ниже, чем у учащихся ФМ и ЛГ профилей $(\mathrm{p}<0,05)$, что свидетельствуют о более успешной адаптации представителей ИФ профиля к обучению.

Таким образом, степень напряжения механизмов регуляции сердечного ритма у подростков в процессе долговременной адаптации к обучению по разным профильным программам различается:

- увеличение напряжения механизмов вегетативной регуляции у учащихся физико- 
Вестник Новосибирского государственного педагогического университета Novosibirsk State Pedagogical University Bulletin

математического профиля отмечается в 10 классе и сохраняется до конца обучения;

- в химико-биологическом профиле напряжение механизмов вегетативной регуляции увеличивается у учащихся в 10 классе и снижается в 11 классе;

- у учащихся лингвистического профиля значительное напряжение механизмов вегетативной регуляции наблюдается с 9 по 11 класс;
- в историко-филологическом профиле у учащихся напряжение механизмов вегетативной регуляции наблюдается в 9 классе и снижается к 10 классу.

Представленные в настоящей работе результаты свидетельствуют о выраженном влиянии специфики учебной нагрузки на организм подростков на разных этапах профильного обучения.

\section{СПИСОК ЛИТЕРАТУРЫ}

1. Айзман Р.И., Рубанович В.Б., Суботялов М.А. Основы медицинских знаний и здорового образа жизни: учебное пособие. - Новосибирск, 2010. - 286 с.

2. Баевский Р.М., Берсенев Е.Ю., Берсенева И.А. Медленные волны сердечного ритма, как индикатор возрастного развития детей и подростков / Медленные колебательные процессы в организме человека. Теоретические и прикладные аспекты нелинейной динамики в физиологии. Сб. материалов III Симпозиума и Школы. - Новокузнецк, 2001. - С. 105-109.

3. Баевский Р.М. и др. Анализ вариабельности сердечного ритма при использовании различных электрокардиографических систем: метод. рекомендации // Вестник аритмологии. 2001. - T. 24. - C. 69.

4. Быструшкин С.К., Айзман Р.И., Афтанас Л.И. Особенности организации внимания и эмоционального восприятия у детей в норме и при нарушениях интеллектуального развития // Бюллетень Сибирского отделения Российской академии наук. - 2007. - № 3. C. $159-162$.

5. Гиренко Л.А., Головин М.С., Колмогоров А.Б., Айзман Р.И. Функциональные резервы юношей, занимающихся лыжным спортом // Вестник Новосибирского государственного педагогического университета. - 2012. - № 6. - С. 45-50.

6. Игишева Л.Н., Галлеев А.Р. Комплекс ORTO EXPERT, как компонент здоровьесберегающих технологий в образовательных учреждениях: Методическое руководство. - Кемерово, 2003. $-36 \mathrm{c}$.

7. Казин Э.М., Блинова Н.Г., Душенина Т.В., Галеев А.Р. Комплексное лонгитудинальное исследование особенностей физического и психофизиологического развития учащихся на этапах детского, подросткового и юношеского периодов онтогенеза // Физиология человека. - 2003.- Т. 29, № 21. - С.70-76.

8. Мукатаева Ж.М. Морфофункциональная характеристика сельских детей и подростков разного пола северного Казахстана // Вестник Новосибирского государственного педагогического университета. - 2013. - № 2(12).- С. 70-79.

9. Пушкарёва Е.А., Судоргина Л.В. Культура самоопределения: адаптационные механизмы личности // Вестник Новосибирского государственного педагогического университета. 2012. - № 4. - С. 80-87.

10. Сафронова А.И., Вахмистрова А.В., Никулин В.Н., Каримова Л.Н. Функциональное состояние вегетативной нервной системы школьников и гимназистов в условиях комплекс- 
Вестник Новосибирского государственного педагогического университета Novosibirsk State Pedagogical University Bulletin

ного воздействия факторов школьной и окружающей среды // Гигиена и санитария. -2009. - № 4. - С 55-58.

11. Степанова М.И., Александрова И.Э., Седова А.С. Новая шкала трудности учебных предметов в общеобразовательной школе // Вестник образования России. - 2004. - № 5. C. $43-48$.

12. Stauss H.M. Physiologic mechanisms of heart rate variability. Rev Bras Hipertens 14. - 2007. pp. 8-15. 


\title{
UDC 614+371.7
}

\section{ADAPTATION OF TEENAGERS IN THE COURSE OF TRAINING ACCORDING TO DIFFERENT PROFILE PROGRAMS}

\author{
T. V. Vasina, N. N. Koshko (Kemerovo, Russia)
}

The article presents the results of research of students adaptive changes occurring in the training process according to different profile programs from 8 to 11 . Purpose of the article is to justify that adaptation of high school students to the process of training depends on the complexity and content of the training activities. It is shown that at preprofile and profile training stages of manifestation of adaptive responses in adolescents are different. With an increase in the teaching load the transition of systems of vegetative regulation of a cardiac rhythm of the pupils of all profiles increases. The highest voltage is found at students of linguistic and physical-mathematical profiles.

Key words: adaptation, the students, the profile of training, heart rate variability, stress mechanisms of autonomic regulation.

\section{REFERENCES}

1. Aizman R.I., Rubanovich V.B., Subotyalov M. A. Osnovy meditsinskikh znanii i zdorovogo obraza zhizni: uchebnoe posobie [Bases of medical knowledge and healthy way of life]. Novosibirsk, 2010, $286 \mathrm{p}$

2. Bayevsky R.M., Bersenev E.J., Berseneva I.A. Medlennye volny serdechnogo ritma, kak indikator vozrastnogo razvitiya detei i podrostkov [Slow waves of heart rate as an indicator of the age of children and adolescents]. Slow oscillatory processes in the human body. Teoreticheskie and applied aspects of nonlinear dynamics in physiology. Sat Materials III Symposium and School, Novokuznetsk, 2001, pp. 105-109.

3. Bayevsky R.M. etc. Analiz variabel'nosti serdechnogo ritma pri ispol'zovanii razlichnykh elektrokardiograficheskikh sistem: metod. rekomendatsii [Analysis of heart rate variability using different electrocardiographic systems: the method. recommendations]. Herald arrhythmology, 2001, vol. 24, p. 69.

4. Bystrushkin S.K., Aizman R.I., Aftanas L.I. Osobennosti organizatsii vnimaniya i emotsional'nogo vospriyatiya $\mathrm{u}$ detei $\mathrm{v}$ norme i pri narusheniyakh intellektual'nogo razvitiya [Features of the organization of attention and emotional perception at children in norm and at infringements of intellectual development]. Bulletin of the Siberian branch of the Russian academy of sciences, 2007, no. 3, pp. 159-162.

5. Girenko L.A., Golovin M.S., Kolmogorov A.B., AjzmanR.I. Funktsional'nye rezervy yunoshei, zanimayushchikhsya lyzhnym sportom [Functional reserves of the young men engaged skiing]. Novosibirsk State Pedagogical University Bulletin. 2012, no. 6, pp. 45-50.

6. Igisheva L.N., Galleev A.R. Kompleks ORTO EXPERT, kak komponent zdorov'esberegayushchikh tekhnologii v obrazovatel'nykh uchrezhdeniyakh. Metodicheskoe rukovodstvo [The complex 
ORTO EXPERT, as a component of health-saving technologies in educational institutions. A guide]. Kemerovo, 2003, 36 p.

7. Kazin E.M., Blinov N., Dushenina T.V., Galeev A.R. Kompleksnoe longitudinal'noe issledovanie osobennostei fizicheskogo i psikhofiziologicheskogo razvitiya uchashchikhsya na etapakh detskogo, podrostkovogo i yunosheskogo periodov ontogeneza [The complex features a longitudinal study of physical and psycho-physiological development of pupils at the stages of child, adolescent and youth periods of ontogenesis]. Human Physiology, 2003, vol. 29, no. 21, pp. 70-76.

8. Mukataeva Zh.M. Morfofunktsional'naya kharakteristika sel'skikh detei i podrostkov raznogo pola severnogo Kazakhstana [Morphological and functional characteristic of rural children and teenagers of the different sex of northern Kazakhstan]. Novosibirsk State Pedagogical University Bulletin, 2013, no. 2(12), pp. 70-79.

9. Pushkareva E.A., Sudorgina L.V. Kul'tura samoopredeleniya: adaptatsionnye mekhanizmy lichnosti [Culture of self-determination: adaptable mechanisms of the person]. Novosibirsk State Pedagogical University Bulletin. 2012, no. 4, pp. 80-87.

10. Safronov A.I., Vahmistrova A.V., Nikulin V., Karimov L.N. Funktsional'noe sostoyanie vegetativnoi nervnoi sistemy shkol'nikov i gimnazistov $\mathrm{v}$ usloviyakh kompleksnogo vozdeistviya faktorov shkol'noi i okruzhayushchei sredy [The functional state of the autonomic nervous system and high-school students in a complex influence factors of school and environment]. Hygiene and sanitation, 2009, no. 4, pp. 55-58.

11. Stepanova M.I., Alexandrov I.E., Sedov A. Novaya shkala trudnosti uchebnykh predmetov v obshcheobrazovatel'noi shkole [The new scale of difficulty of subjects in secondary school]. Journal of Education of Russia, 2004, no. 5, pp. 43-48.

12. Stauss H.M. Physiologic mechanisms of heart rate variability. Rev Bras Hipertens 14, 2007, pp. 8 15.

Vasina Eugeniya Vladimirovna, Ph.D., the heard of the laboratory of development of health-related activities within the vocational education, Kuzbass Regional development institution of vocational education.

E-mail: ev-va08@mail.ru

Koshko Nataliya Nikolayevna, Ph.D., the lecturer in human and animal physiology and valeology, Kemerovo State University.

E-mail: koshko80@mail.ru 